\title{
The Advanced Practice Nurse as a Member of the Cardiovascular Team
}

\author{
Kristine Anne Scordo*, Julie A Stanik-Hutt, Sheila Melander, Janet F Wyman, Kathy Madgic and George P Rodgers \\ Cardiovascular Team Council and Section, American College of Cardiology, Wright State University, Loveland, OH, USA \\ *Corresponding author: Kristine Anne Scordo, Professor and Director, Wright State University, Nursing, 915 Murle Lane, Loveland, OH-45140, USA, Tel: 5136839233, \\ E-mail: kscordo@cinci.rr.com
}

Rec date: Apr 09, 2016, Acc date: Oct 24, 2016, Pub date: Nov 1, 2016

Copyright: $\odot 2015$ Scordo KA et al. This is an open-access article distributed under the terms of the Creative Commons Attribution License, which permits unrestricted use, distribution, and reproduction in any medium, provided the original author and source are credited.

\begin{abstract}
Team-based care is paramount to meet the mission of the American College of Cardiology which is to transform cardiovascular care and improve heart health. Advanced practice registered nurses (APRN) are integral to this team. Although the recent ACC 2015 health policy statement on cardiovascular team-based care address contributions of all members of the team, further information that defines APRNs, their contributions to the cardiovascular team and barriers to practice are needed. Therefore, the purpose of this manuscript is to further explain the role of the APRN as a member of the cardiovascular team with a focus on the certified nurse practitioner and clinical nurse specialist within the United States.
\end{abstract}

Keywords Advanced practice nursing; Nurse practitioner; Clinical nurse specialist

\section{Introduction}

Team-based care is paramount to meet the mission of the American College of Cardiology (ACC) which is "to transform cardiovascular care and improve heart health" [1]. In the recent ACC 2015 health policy statement on cardiovascular team-based care, team members are collectively known as advanced practice providers (APPs) and include physician assistants (PAs), pharmacists (PharmDs) and advanced practice registered nurses (APRNs) [1]. Each member makes unique contributions towards patient care. Although the ACC 2015 health policy statement provided an overview of the education, training and role of these professions, the scope of the paper did not permit an in-depth discussion regarding aspects of each role, outcomes of care, barriers to practice and contributions of each role to the cardiovascular team (CV team).

The Cardiovascular Team Section Leadership Council (CVT Section Leadership Council) has proposed a series of papers written by each of the Section's profession-based work groups to address this need. Therefore, the purpose of this manuscript, written by the APRN work group on behalf of the CVT Section Leadership Council, is to provide a more in depth review of the role of an APRN as a member of the CV team within the United States.

\section{Defining the Role of the Advanced Practice Registered Nurse}

In response to the need to develop standardized licensure across states and address educational criteria for entry into advanced practice and requirements for certification, the Consensus Model for APRN Regulation was developed in 2008 [2]. Prior to this document, there was no uniform model of regulation of APRNs across the states. That is, each state independently determined various criteria to practice as an APRN which created significant barriers for APRNs to move from one state to another and also decreased access to care for patients [2]. This landmark document seeks to simplify and unify regulation of advanced nursing practice and was endorsed by 48 national organizations. According to the Consensus Model for APRN Regulation, an APRN must be educated, certified and licensed to practice in one of the following roles: certified registered nurse anesthetist (CRNA), certified nurse midwife (CNM), certified nurse practitioner (CNP) or clinical nurse specialist (CNS). Each role differs based on published role competencies and defines the activities in which the APRN will engage. For example, CNSs are experts in nursing practice whose role it is to improve care of individual patients and populations through application of their expertise, development of nursing staff, and systems improvement. Conversely, the role of a nurse practitioner is to provide direct health care services. In addition to choosing a role, an APRN must choose one of the following patient populations as a focus of their practice (called population foci). These population foci include: family/individual across the lifespan, adultgerontology, neonatal, pediatrics, women's health/gender-related, or psychiatric mental health. The role and population focus form the basis for the APRNs education, certification and licensure. National board certification examinations verify that an APRN has mastered entry level competencies to practice within the role and population focus in which the APRN was educated. National board certification examinations are offered by the American Nurses Credentialing Center (ANCC), the American Association of Nurse Practitioners (AANP), the American Association of Critical Care Nurses (AACN) and the Pediatric Nursing Certification Board (PNCP).

APRNs receive formal education with a graduate degree (master's or doctoral) or post-graduate certificate that includes both didactic and a minimum of faculty-supervised 500 clinical hours. The degree is awarded by an academic institution accredited by a nursing or nursingrelated accrediting organization recognized by the U.S. Department of Education (USDE) and/or the Council for Higher Education Accreditation (CHEA) [2]. To achieve this accreditation, educational programs must meet national nursing certifying body requirements set forth by organizations such as The National Association of Clinical Nurse Specialists (NACNS) [3], American Association of Colleges of Nursing (AACN) and National Organization of Nurse Practitioner Faculties (NONPF) [4]. 
According to the Consensus Model, a CNS integrates and influences care through three spheres of influence: patient, nurse and system, with a primary goal of continuous improvement of patient outcomes and nursing care. "The CNS is responsible and accountable for diagnosis and treatment of health/illness states, disease management, health promotion, and prevention of illness and risk behaviors among individuals, families, groups, and communities" [2]. Clinical Nurse Specialists have a depth of expertise within their patient population foci and sometimes within specialty areas as well (e.g. oncology, critical care, orthopedics, etc.). In addition to their clinical expertise, CNSs possess skills and knowledge that include evidenced based practice, collaboration, education, mentoring and leadership to function as a change agent [5]. As a change agent, CNSs assist organizations transform themselves by focusing on organizational effectiveness, improvement and development. As such, clinical nurse specialists are paramount in evaluating processes and procedures that ensure best practice standards and patient safety.

Certified nurse practitioners provide direct care along the wellnessillness continuum in primary and acute care settings. CNPs diagnose and treat patients "with undifferentiated symptoms as well as those with established diagnoses" [2]. These practitioners provide initial, ongoing, and comprehensive care, that includes taking comprehensive histories, performing physical examinations and other health assessment and screening activities, along with diagnosing, treating, and managing patients with acute and chronic illnesses and diseases [2]. Both CNS and NP practice are built on a foundation of nursing education and practice; as such the retention of nursing perspective accompanies APRN practice. Thus, in addition to diagnosis, treatment and symptom management, APRNs practice includes patient centered care, self-care and symptom management, health promotion and disease management, and coordination of patient care along with a strong pattern of interprofessional communication and collaboration.

Depending upon their education, training and national certification, certified nurse practitioners are prepared to practice as primary care nurse practitioners or acute care nurse practitioners (Figure 1). According to the NONPF position paper on acute care and primary care nurse practitioner practice [6]:

"The main emphasis of primary care NP (PCNP) educational preparation is on comprehensive, chronic, continuous care characterized by a long term relationship between the patient and PCNP. The PCNP provides care for most health needs and coordinates additional health care services that would be beyond the PCNP's area of expertise. In contrast, the ACNP educational preparation focuses on restorative care that is characterized by rapidly changing clinical conditions. The ACNP provides care for unstable chronic conditions, complex acute illnesses, and critical illnesses."

Thus, in a cardiovascular practice, depending upon their educational preparation, responsibilities of CNPs would include rounding, ordering, performing, supervising and interpreting laboratory and imaging studies along with performing histories and physicals, diagnosing, prescribing medication, performing procedures and making appropriate referrals. CNSs would lead quality assurance initiatives such as improving door-to-balloon time and reducing ventilator-associated pneumonia, increasing adherence to cardiac rehabilitation and reducing avoidable readmissions along with research study management. Additional activities of CNS and CNP would include patient and family education and counseling for health promotion, disease prevention and disease management along with discharge planning. These activities are vital aspects not only for a team-based approach to patient care, but also value-based health care.

APRNs may choose to specialize in a clinical area, such as a cardiovascular care. Specialization is optional and builds upon the competencies of the role and population focus but does not expand the APRNs scope of practice (SOP) beyond their initial role and population preparation (Figure 1) [2]. For instance, an adult gerontology acute care nurse practitioner (AG-ACNP) who completes a fellowship in cardiology does not become a cardiac nurse practitioner, nor do they gain the ability to provide cardiac care for all age groups and population. Similarly a pediatric cardiologist would not be expected to care for a 70 year old patient having an acute STsegment myocardial infarction.

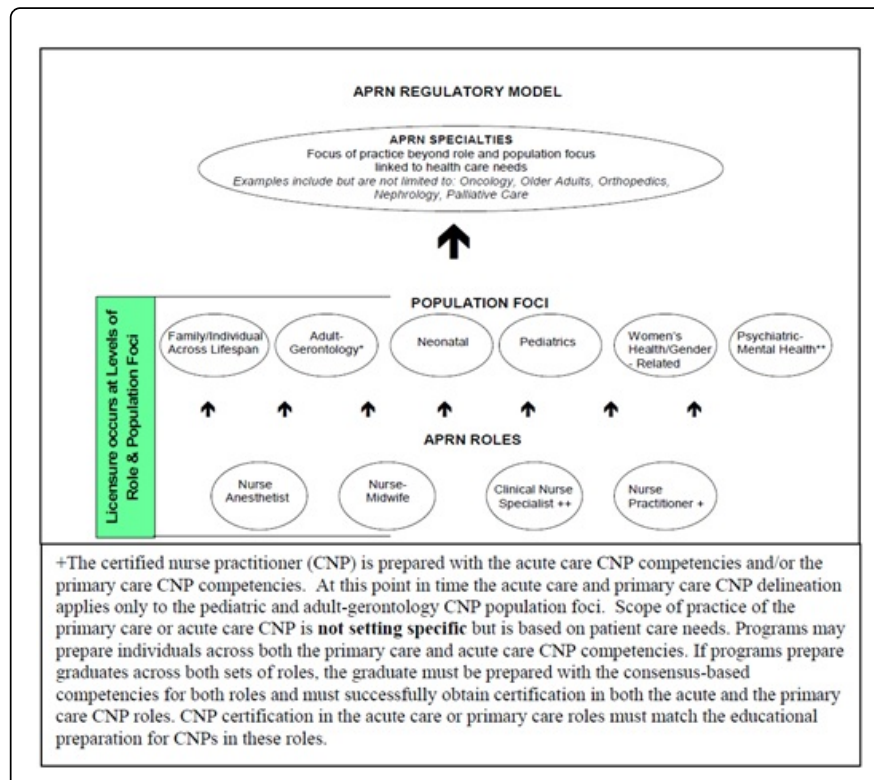

Figure 1: From APRN Consensus Work Group and National Council of State Boards of Nurses. Consensus model for APRN regulation: licensure, accreditation, certification and education.

Cardiovascular specialty preparation may be completed in combination with APRN graduate education or through post-graduate education. For instance, APRNs who want to specialize in CV nursing, can attend graduate programs that provide additional elective courses and clinical experiences in cardiology, or they can complete a postgraduate nursing fellowship in cardiology. However, presently no national accreditation is available for graduate nursing fellowship programs. The use of the term fellowship as opposed to residency helps to clarify that the education and licensure of an APRN is not contingent on postgraduate training and helps prevent confusion with the physician training model that mandates a residency in order to practice [7]. The APRN workgroup of the CV Team Counsel and Section of ACC is currently seeking to develop competencies specific to advanced practice nurses that are similar to the ACCF's Cardiology Competency Statements (COCATS) for fellows in training. These APRN specific core competencies would include clusters of knowledge, values, skills and abilities that correlate with effective performance in the care of the cardiovascular patient within a specific population foci. These core competencies can then be formalized and used as a curricular guiding document for organizations caring for $\mathrm{CV}$ patients. Similar to COCATS, this would lead to more focused, cost-effective 
training that is tailored for APRNs leading to improved evidence-based practice and quality of care. In addition, these core competences can be the impetus for a standardized national examination that will certify post-graduate nurses in a cardiovascular specialty, thus ensuring appropriate knowledge and skills.

\section{Scope of Practice of APRNs}

Scope of practice is a legal term and can be defined as a set of rules, regulations and boundaries within which fully qualified APRNs may practice [8]. APRN practice is regulated in accordance with state statutes and interpreted by administrative rules. The aim of this regulation is protection of the public. According to the APRN Consensus Model, scope of practice (SOP) is determined by graduate level education and national certification based on role delineation studies. Patient care needs and not practice setting forms the foundation for competencies, education and certification. This is also supported by the National Organization of Nurse Practitioner Faculties (NONPF) position statement that states that SOP is based on formal APRN education rather than education, practice or post graduate onthe-job training obtained prior to APRN education [9]. For example, a primary care NP (Family primary care NP, Pediatric primary care NP, Adult-gerontologic primary care NP) might see stable heart failure patients and manage hypertension, while an acute care NP would manage patients with decompensated heart failure and hypertensive crisis. Scope of practice statements are further elucidated by professional organizations such as AANP [10], American Association of Critical Care Nurses (AACN) [11,12], The Academy of MedicalSurgical Nurses (AMSN) [13], and The National Association of Pediatric Nurse Practitioners (NAPNAP) [14,15]. Further clarification between acute care and primary care NPs SOP can also be found in the NONPF September 2011 position paper [9]. As the Consensus Model is implemented, stakeholders are seeking to modify state nurse practice acts to comply with the model recommendations.

\section{Advanced Nursing Practice: Outcomes of Care}

As APRNs assume an increasing role in providing care to cardiovascular patients, measuring the impact of their care is essential to assess the effectiveness of their contributions to the CV team. The scientific statement from the American Heart Association on the evolution of clinical cardiology identifies that the integration of APRNs into the cardiac critical care team contribute to care continuity and cost effectiveness as well as improved staffing of critical care units [16]. Multiple studies demonstrate that APRNs in a variety of settings provide safe, quality cost effective care and are readily accepted by patients who are satisfied with their care $[17,18]$. In a recent systematic review of published literature between 1990 and 2008 on outcomes of care provided by APRNs in concert with physicians, APRNs provided similar, and in some cases better care than provided by physicians alone [19]. APRNs were found to reduce length of hospital stay, improve functional status, improve lipid and blood pressure control and reduce hospital readmissions [19]. In a nurse-directed education approach that focused on diet, lifestyle modification, daily weight management and medication adherence for heart failure patients, APRNs were found to improve patients quality of life [20]. In a comparison of physician-based model of heart failure management versus an NP-led disease management model, the nurse practitioner model resulted in reduced use of inpatient care and mortality [21].

Case management by clinical nurse specialists demonstrated a decrease in hospital stay compared to those that were not managed by
CNSs [22]. Systematic reviews of research found that CNSs reduce hospital costs and lengths of stay, reduce frequency of emergency room visits improve pain management practices, reduce complications in hospitalized patients and increase patient satisfaction with nursing care $[18,19]$. The influence of APRNs and PAs on the delivery of guideline-recommended therapies for outpatients with heart failure noted that staffing with two or more APRNs and PAs per cardiology practice was associated with a greater use of implantable cardioverterdefibrillator therapy and delivery of HF education [23]. APRNdirected HF discharge programs that use home follow-up protocols using telephone intervention significantly improved QOL, HF management as well as reduced costs and readmissions [24-27]. APRN managed cardiac surgery follow-up model of care compared with a standard model of primary care provider follow-up for coronary artery bypass graft surgery patients was shown to improve patient satisfaction, QOL and patient symptoms [28]. Although more research with greater sample sizes are needed specific to cardiovascular nursing, as members of the CV team, studies support that APRNs provide safe, effective quality, cost effective care. With the knowledge that APRNs provide added value to existing care systems and contribute to quality and cost effectiveness, many organizations and practices have implemented or plan to implement care systems that incorporate greater use of APRNs. With over three quarters of cardiology practices now integrated within larger health systems and the increasing emphasis on quality of care and patient centered outcomes, the unique skills of APRNs are vitally important to the success of a cardiovascular service line. Furthermore, CMS and other payors are moving in the direction payment for value rather than volume. In 2014 Congress passed legislation to replace the flawed SGR (Sustained Growth Rate) with MACRA (Medicare Access and CHIP Reauthorization) which is projected to convert the old fee for service model with compensation largely based on quality outcomes. Already ACOs and Bundled Payments plans are oriented towards incentives for achieving improved outcomes. To meet these new demands CNSs are highly skilled in measuring patient centered quality outcomes and techniques in teambased quality improvement and CNPs provide more cost effective care with an emphasis on patient and family education that facilitates success as patients transition to home and self-care. These CV team members are essential to clinical practice in this new era of value-based healthcare.

\section{Models of Team-Based Care}

As defined in an IOM report [29] on core values of team-based care and supported by the AANP [30],

"Team-based health care is the provision of health services to individuals, families, and/or their communities by at least two health providers who work collaboratively with patients and their caregivers to the extent preferred by each patient to accomplish shared goals within and across settings to achieve coordinated, high-quality care" [29].

According to this definition, team-based care could simply be an APRN and a cardiologist, or might include larger teams with PAs, pharmacists, dietitians, psychologists, social workers, respiratory therapy, occupational therapy and others. In either situation, teambased care is a multidisciplinary, nonhierarchical collaborative that is centered on a patient's needs [30] and needs to be preceded by mutual trust and respect for one another roles. Therefore, health care teams are dynamic, and depending upon a patient's needs may include a physician, pharmacist, advanced practice nurse or other member of the 
health team. As a member of the CV team, the role of the APRN varies and may include advocate, clinician, consultant, educator, evaluator, leader, manager, partner and transformer [31].

There are multiple practice settings where APRNs may participate in team-based care. These include, but are not limited to academic centers, private cardiology practices, acute care hospitals as unit-based providers, hospitalist or intensivist, in acute chest pain clinics, cardiac rehabilitation programs, transplant programs, cardiovascular surgery, electrophysiology services, and a variety of preventive cardiology services such as lipid, Coumadin, hypertension, heart failure clinics and other prevention programs. According to a the ACC's Practice Census Study conducted in September 2010, of a total of 1812 NPs and $106 \mathrm{CNS}$, the majority of these APRNs practice within a group practice [32]. Within these practice settings, are multiple team-based care models that include case management, interdisciplinary primary care, disease management, proactive rehabilitation, transitional care, chronic disease self-management, comprehensive inpatient care and early discharge hospital-to-home [33]. A detailed discussion of these team-based models is outside the scope of this article.

Examples specific to cardiology practices include the Veterans Affairs (VA) and The Duke University Health Systems. In the VA system, APRNs help coordinate care for inpatient and outpatient services. In specialist cardiology clinics where NPs serve as primary providers, more patients achieved ATP III (Adult Treatment Panel) goals than those managed by physicians [34]. To increase access to care and improve patient satisfaction, The Duke University Health System's Department of Cardiovascular Medicine adopted an interprofessional team-based approach [35]. As compared to the previous model where clinics were run by physicians, the new model allows APRNs to work to the top of their education and training. Not all cardiology practices, however, embrace team-based care or employ APRNs. This may be due to lack of awareness of the effectiveness of APRNs, financial issues, or issues related to practice acts. Research is needed that identify barriers to the development of team-based cardiovascular care, identify perceptions of team-based care effectiveness and define the best approaches to institute team-based care.

\section{Barriers to APRN Practice within the CV Team}

According to the Institute of Medicine (IOM), "Advanced Practice Nurses should practice to the full extent of their education and training" [36]. APRNs have the training and skills to make valid contributions to the $\mathrm{CV}$ team. To accomplish this, the IOM recommends removing unnecessary barriers to APRN practice. This position is supported by the Federal Trade Commission which urges state legislators to eliminate unnecessary restrictions on APRN scope of practice [37]. Multiple national nursing organizations, such as the American Association of Nurse Practitioners (AANP) and AACN (American Association of Critical Care Nurses) along with the American Association of Retired Persons (AARP) [38] actively support regulatory policies which increase patient access to APRN care. The Heart Failure Society of American (HFSA) and the American Association of Heart Failure Nurses (AAHFN) strongly advocate "for the removal of scope-of-practice barriers to allow APRNs to practice to the full extent of their education and training" [39].

APRNs contributions as a CV team member are often hindered by governmental or organizational policies. Some state licensure regulations require detailed care agreements or an attestation, a document containing the name and license number of a collaborating or supervising physician. Others limit APRN prescribing to formularies, and some states prohibit prescribing physical therapy, occupational therapy and rehabilitative services. Some states limit the forms an APRN can sign or certify. In some states the nurse practice acts lack the clarity needed to appropriately authorize APRNs to provide the advanced services that they are trained to deliver. Not all hospitals and health care systems credential APRNs to admit patients or to perform procedures that are within their scope of practice. APRN services are also limited by reimbursement policies. Not all payers reimburse for APRN services; some sharply discount rates paid to APRNs even though the service provided was identical to that which would have been provided by a physician [40]. APRNs are highly qualified, independently licensed health care professionals who make unique contributions to care teams. As recognized by the IOM, the American College of Physicians, the American College of Cardiology and many other organizations, allowing APRNs to practice to the full extent of their education and training would most likely allow physicians to better utilize their skills by focusing on the most challenging and complex cases [41-45]. Just as APRNs recognize the limits of their practice knowledge and the need for physician expertise, physicians should acknowledge APRNs capacities and unique contributions so that all health care providers' skills can be used most appropriately to address the complex needs of patients with cardiovascular problems [46-50].

\section{Summary}

APRNs are highly qualified health care providers, who have been shown to deliver high quality, cost effective care. APRNs come to the cardiovascular care team with unique skills that can add value to the prevention and management of cardiovascular disease. Creating a practice environment in which APRNs are allowed to practice to the full extent of their education and training can increase patient access to care, improve care quality and consequently decrease long term healthcare costs for patients with cardiovascular problems.

\section{Acknowledgements}

The authors wish to thank the following individuals for their thought full review and comments: Nancy C. Berg, MA, RN, ANP-BC, AACC; Sandra Oliver-McNeil DNP, ACNP-BC, CHFN, AACC; Margo B. Minissian, PhDc, ACNP, CLS, AACC, FAHA; Kelli Bohannon, BS; Kay Blum PhD, CRNP.

\section{References}

1. Brush JE , Handberg E, Biga C, Birtcher KK, Bove AA, et al. (2015) Health Policy Statement: 2015 ACC Health Policy Statement on Cardiovascular Team-Based Care and the Role of Advanced Practice Providers. J Am Coll Cardiol 65: 2118-2136.

2. (2008) APRN Joint Dialogue Group Report. Consensus model for APRN regulation: Licensure, accreditation, certification, \& education.

3. (2015) Criteria for the Evaluation of Clinical Nurse Specialist Master's, Practice Doctorate, and Post-Graduate Certificate Educational Programs. The National Association of Clinical Nurse Specialists.

4. (2015) National Task Force on Quality Nurse Practitioner Education (2012) Criteria for evaluation of nurse practitioner programs. Washington, DC: National Organization of Nurse Practitioner Faculties.

5. Soltis LM (2015) Role of the Clinical Nurse Specialist in Improving Patient Outcomes After Cardiac Surgery. AACN Adv Crit Care 26: 35-42.

6. (2011) National organization of nurse practitioner faculties. Statement of acute care and primary care nurse practitioner practice. 
7. (2014) Nurse practitioner perspective on education and post-graduate training.

8. Kleinpell RM, Hudspeth R, Scordo KA, Magdic K (2012) Defining NP scope of practice and associated regulations: Focus on acute care. J Am Acad Nurse Pract 24: 11-18.

9. (2011) National Organization of Nurse Practitioner Faculties. Statement on acute care and primary care nurse practitioner practice. Washington.

10. (2010) American Academy of Nurse Practitioners. Scope of practice for nurse practitioners.

11. Bell L (2012) American Association of Critical Care Nurses (AACN) Scope and Standards of Practice for the Acute Care Nurse Practitioner. American Association of Critical-Care Nurses.

12. Bell L (2014) American Association of Critical Care Nurses (AACN) Scope and Standards of Practice for the Critical Care Clinical Nurse Specialist. American Association of Critical-Care Nurses.

13. (2012) Academy of Medical-Surgical nurses. Scope and Standards of Medical-Surgical Clinical Nurse Specialist Practice. (2nd edn) Academy of Medical-Surgical Nurses, Pitman, NJ.

14. (2002) Nurse Practitioner Primary Care Competencies In Specialty Areas: Adult, Family, Gerontological, Pediatric, And Women's Health [e-book]. Rockville, MD: U.S. Dept. of Health and Human Services, Health Resources and Services Administration.

15. (2008) Pediatric Nursing: Scope And Standards Of Practice [e-book]. Silver Spring, Md: American Nurses Association.

16. Morrow DA, Fang JC, Fintel DJ, Granger CB, Katz JN, et al. (2012) Evolution of critical care cardiology: transformation of the cardiovascular intensive care unit and the emerging need for new medical staffing and training models: a scientific statement from the American heart association. Circulation 126: 1408-1428.

17. Kleinpell R (2013) Outcome assessment in advanced practice nursing (3rd edn) Springer, New York.

18. Baldwin KM, Clark AP, Fulton J, Mayo A (2009) National validation of the NACNS clinical nurse specialist core competencies. J Nurs Scholarsh 41: 193-201.

19. Newhouse RP, Stanik-Hutt J, White KM, Johantgen M, Bass EB, et al. (2011) Advanced Practice Nurse Outcomes 1990-2008: A Systematic Review. Nurs Econ 29: 230-251.

20. Kutzleb J, Reiner D (2006) The impact of nurse-directed patient education on quality of life and functional capacity in people with heart failure. J Am Acad Nurse Pract 18: 116-123.

21. Lowery J, Hopp F, Subramanian U, Wiitala W, Welsh DE, et al. (2012) Evaluation of a nurse practitioner disease management model for chronic heart failure: a multi-site implementation study. Congest Heart Fail 18: 64-71.

22. Topp R, Tucker D, Weber C (1998) Effect of a clinical case manager/ clinical nurse specialist on patients hospitalized with congestive heart failure. Nurs Case Manag 3: 140-145.

23. Albert NM, Fonarow GC, Yancy CW, Curtis AB, Stough WG, et al. (2010) Heart failure: Outpatient Cardiology Practices With Advanced Practice Nurses and Physician Assistants Provide Similar Delivery of Recommended Therapies. Am J Cardiol 105: 1773-1779.

24. Naylor MD, Brooten DA, Campbell RL, Maislin G, McCauley KM, et al. (2004) Transitional care of older adults hospitalized with heart failure: a randomized, controlled trial. J Am GeriatrSoc 52: 675-684.

25. Stauffer BD, Fullerton C, Fleming N, Ogola G, Herrin J et al. (2011) Effectiveness and cost of a transitional care program for heart failure. Arch Intern Med 171: 1238-1243.

26. Blue L, Lang E, McMurray JJ, Davie AP, McDonagh TA, Murdoch DR, et al. (2001) Randomised controlled trial of specialist nurse intervention in heart failure. BMJ 323:715-718.

27. Brandon AF, Schuessler JB, Ellison KJ, Lazenby RB (2009) Online Article: The effects of an advanced practice nurse led telephone intervention on outcomes of patients with heart failure. Appl Nurs Res 22: e1-e7.
28. Sawatzky LA, Christie S, Singal, RK. (2013) Exploring outcomes of a nurse practitioner-managed cardiac surgery follow-up intervention: a randomized trial. J Adv Nurs 69: 2076-2087.

29. Mitchell PH, Wynia MK, Golden R McNellis B, Okun S, et al. (2012) Core principles \& values of effective team-based health care. Institute of Medicine, Washington, DC.

30. (2013) American Association of Nurse Practitioners. Nurse practitioners and team based care.

31. Golden A, Miller KP (2013) Championing Truly Collaborative TeamBased Care. Ann Intern Med 159: 642: 643.

32. (2011) American College of Cardiology Practice Census Study.

33. Fletcher GF, Berra K, Fletcher BJ, Gilstrap L, Wood MJ (2012) The integrated team approach to the care of the patient with cardiovascular disease. Curr Probl Cardiol, 37: 369-397.

34. Khatana SA, Jiang L, Wu WC (2014) A comprehensive analysis of dyslipidemia management in a large health care system. J Eval Clin Pract 20: 81-87.

35. (2013) Putting the Skills, Knowledge and Experience of APRNs to Full Use. Robert Wood Johnson Foundation. Princeton, NJU.

36. (2011) IOM (Institute of Medicine). The Future of Nursing: Leading Change, Advancing Health. National Academy of Sciences, Washington, DC: The National Academies Press.

37. (2014) Policy Perspectives: Competition Advocacy and the Regulation of Advanced Practice Nurse Practitioners. Federal Trade Commission.

38. (2010) AARP revises policy supplement, updates scope of practice for APRNs. Journal for Nurse Practitioners 6: 559.

39. Lee CS, Greenberg BH, Laramee AS, Ammon SE, Prasun M, et al. (2012) Position Statement: HFSA and AAHFN joint position statement: Advocating for a full scope of nursing practice and leadership in heart failure. Heart Lung 41: 531-533.

40. Safriet BJ (2011) Federal options for maximizing the value of advanced practice nurses in providing quality, cost-effect heath care. In Institute of Medicine, The future of nursing: Leading change, advancing health. The National Academies Press, Washington, DC.

41. Pittman P, Williams B (2012) Physician wages in states with expanded APRN scope of practice. Nursing Research and Practice 671974-671975.

42. (2010) Hiring a Physician Assistant or Nurse Practitioner. Center for Practice Improvement and Innovation. American College of Physicians, Washington DC.

43. Edmunds MW (1978) Evaluation of nurse practitioner effectiveness: An overview of the literature. Eval Health Prof 1: 69-82.

44. Sox HC Jr. (1979) Quality of patient care by nurse practitioners and physician's assistants: A ten-year perspective. Ann Intern Med 91: 459-468.

45. LaRochelle DR (1987) Research studies on nurse practitioners in ambulatory health care: a review 1980-1985. J Ambul Care Manage10: 65-75.

46. (1981) The costs and effectiveness of nurse practitioners. Office of Technology Assessment. U.S. Government Printing Office, Washington, D.C.

47. Ventura MR, Crosby F, Feldman MJ (1991) An information synthesis to evaluate nurse practitioner effectiveness. Mil Med 156: 286-291.

48. Horrocks S, Anderson E, Salisbury C (2002) Systematic review of whether nurse practitioners working in primary care can provide equivalent care to doctors. BMJ 324: 819-823.

49. Laurant M, Reeves D, Hermens R, Braspenning J, Grol R, et al. (2005) Substitution of doctors by nurses in primary care. Cochrane Database Syst Rev 18: CD001271.

50. Stanik-Hutt J, Newhouse RP, White KM, Johantgen M, Bass EB, et al. (2013) Original Research: The Quality and Effectiveness of Care Provided by Nurse Practitioners. The Journal For Nurse Practitioners 9: 492-500.e13. 